\section{Specific Influence of Solvents on the Infrared Spectra of Alcohols}

AleXaNder VerRiJn Stuart*

Physics Department, Unigersity of Michigan. Ann Arbor, Michigan (Received March 17, 1953)

$\mathrm{T}$

HE general influence of dilution on a hydrogen bonding substance is well known to consist of a drastic decrease in intensity of the absorption band connected with the stretching vibration of the bonded group, and the simultaneous appearance and increase in intensity of a band corresponding to the same vibration in the unbonded molecule." The solvents chosen are always nonpolar, and considered to be inert, but specific differences must, of course, exist between them. Few studies have been made of these specific interactions, ${ }^{2}$ and these were made under conditions where interaction occurs only between solute and solvent molecules, but not between solute molecules mutually. In inert solvents this requires very low concentrations. At higher concentrations both associated and free molecules are present, and the intensity of the "monomer" band can be taken as a quantitative measure for the amount of monomers, using the intensity in the very dilute solution as a standard. ${ }^{1}$ During the course of an investigation of a series of alcohols it became apparent that the solvent-solute interaction cannot be entirely neglected. In order to establish the extent of such specific effects a semiquantitative study has been made.

As a representative alcohol propanol-1 was chosen. Spectra of the $\mathrm{OH}$ stretching frequency have been obtained at various concentrations in three nonpolar and three polar solvents, using a Perkin-Elmer Model 21 spectrometer equipped with a rocksalt prism, and a spectrometer designed and built in this laboratory, which was equipped with a LiF prism. The slight absorption of
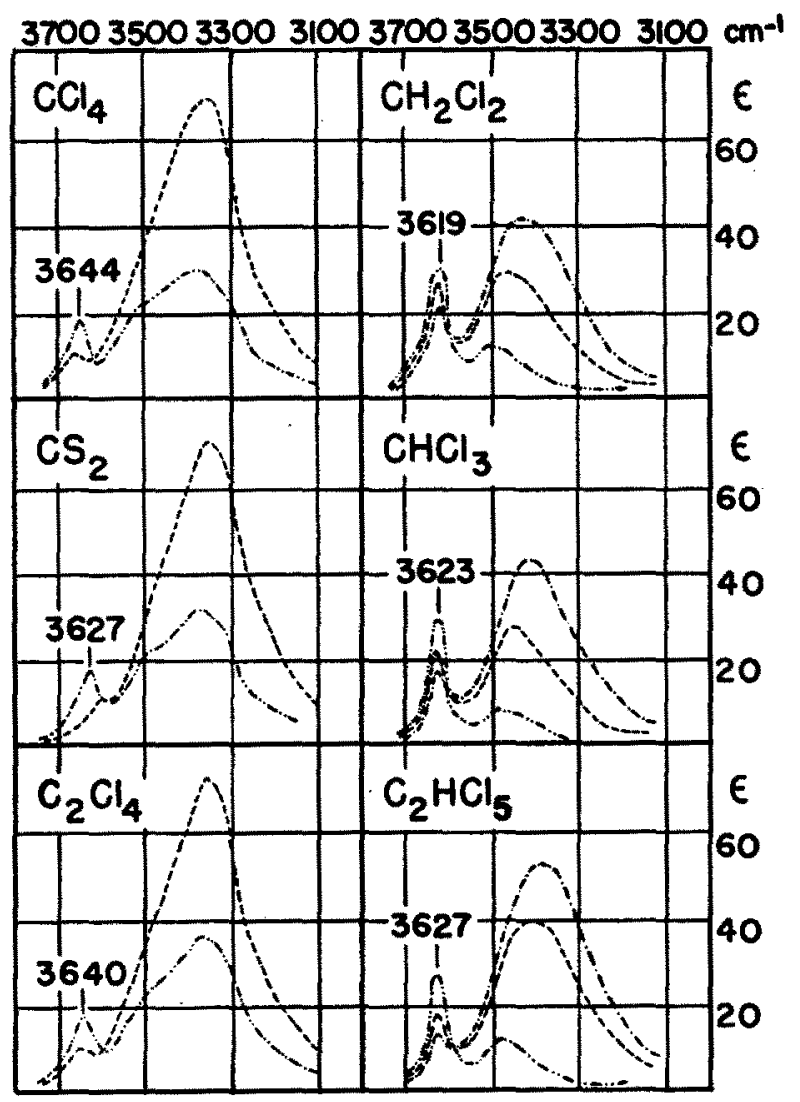

FIG. 1. Propanol $\$$ in six solvents. --2.0 mole/liter, ---1.0 mole/liter - 0.25 mole/hter. Extinction coefficients are given in units $10^{\circ} \mathrm{cm}^{2} /$ mole.
TABLE I. Solvent dependence of the $O H$ stretching frequency. The frequencies are given in $\mathrm{cm}^{-1} ; I_{\text {mon }}$ is given in units $10^{\mathrm{a}} \mathrm{cm}^{2} /$ mole for thecentration of 0.25 mole/liter; the intensity ratios are given for: $A$ mole/liter, $B 1.0$ mole/liter.

\begin{tabular}{|c|c|c|c|c|c|c|}
\hline \multirow[b]{2}{*}{ Nonpolat solvents } & \multirow[b]{2}{*}{$\mathcal{D}$} & \multirow[b]{2}{*}{$y_{\text {mon }}$} & \multirow[b]{2}{*}{$y_{\mathrm{sBn}}$} & \multirow[b]{2}{*}{$I_{\mathrm{mon}}$} & \multicolumn{2}{|c|}{$l_{\mathrm{agn}} / l_{\mathrm{mon}}$} \\
\hline & & & & & $\boldsymbol{A}$ & $B$ \\
\hline $\begin{array}{l}\mathrm{CCl}_{4} \\
\mathrm{C}_{2} \mathrm{Cl}_{4} \\
\mathrm{CS} 2\end{array}$ & $\begin{array}{l}2.24 \\
2.29 \\
2.64\end{array}$ & $\begin{array}{l}3644 \\
3640 \\
3627\end{array}$ & $\begin{array}{l}\text { doublet } \\
\text { doublet } \\
\text { doublet }\end{array}$ & $\begin{array}{l}17 \\
17 \\
17\end{array}$ & $\begin{array}{l}1.77 \\
2.06 \\
1.88\end{array}$ & $\because \cdots$ \\
\hline \multicolumn{7}{|l|}{ Polar solvents } \\
\hline $\begin{array}{l}\mathrm{C}_{2} \mathrm{HCl}_{6} \\
\mathrm{CHCl}_{3} \mathrm{CH}_{2} \mathrm{Cl}_{2}\end{array}$ & $\begin{array}{l}3.82 \\
4.82 \\
8.3\end{array}$ & $\begin{array}{l}3627 \\
3623 \\
3619\end{array}$ & $\begin{array}{l}3410 \\
3450 \\
3470\end{array}$ & $\begin{array}{l}27 \\
28 \\
31\end{array}$ & $\begin{array}{c}0.63 \\
\cdots \\
\cdots\end{array}$ & $\begin{array}{l}2.17 \\
1.23 \\
1.07\end{array}$ \\
\hline
\end{tabular}

the polar solvents in the spectral region studied was compensated for by placing in the reference beam of the spectrometer a cell of variable thickness ${ }^{3}$ containing the pure solvent. The temperature was not controlled, but observed to change less than $1^{\circ} \mathrm{C}$ during the measurements.

The results, which are illustrated in Fig. 1, show four distinct features:

(a) The frequency of the monomer band depends on the solvent used, in all cases.

(b) The association band shows two components in nonpolar solvents (at about 3300 and $3500 \mathrm{~cm}^{-1}$ ), but in the polar solvents only a single peak appears, the position of which varies as a function of the concentration; in nonpolar solvents the $3300 \mathrm{~cm}^{-1}$ peak prevails at high concentrations, the other component at low concentrations.

(c) The intensity of the monomer band is higher in the polar solvents than in the nompolar solvents, where a peak intensity of $25 \times 10^{3} \mathrm{~cm}^{2} /$ mole is never exceeded at any dilution (very dilute solutions are not shown in Fig. 1).

(d) The intensity ratio of association and monomer bands, which is a measure of what might be called the "hydrogen bond breaking power" is different at identical concentrations.

The quantitative aspects of these results are listed in Table I. They indicate that differences exist, not only between the two classes of solvents, but also between the individual members of one class. A correlation with the dielectric constant suggests itself, ${ }^{2 b}$ and this quantity is listed with the results in Table I. In all cases the frequency of the monomer band is shifted to a value lower than the value $3680 \mathrm{~cm}^{-1}$ observed in the vapor spectrum. The assumption that such a shift would indicate hydrogen bonding between solute and solvent ${ }^{2 \mathrm{a}}$ seems too general, but the conclusion seems warranted that the interaction is never negligible. The correlation with the dielectric constant, which is qualitatively perfect for the sequence of these shifts, holds only partially if applied to the bond breaking power. Only for the polar solvents does one find the same sequence of intensity ratios of association and monomer bands (here also the progression of the peak frequencies of the association band is indicative). For the nonpolar solvents the considerably smaller and irregular effect suggests that other factors, such as the individual bond moments of the groups closest to the solute molecule, and the size of the "hole" in the solvent "cage," may also play a part in the mechanism. Unexplained must remain the doubling of the association band in the nonpolar solvents. It seems unlikely that one deals with two different configurations (e.g., dimer and chain polymer) since a similar doubling is not observed for the $\mathrm{OH}$ deformation vibration. Results of an investigation of this motion will be published shortly.

The author is indebted to the Dow Chemical Company for a fellowship in support of this work.

* Now with Koninklijke/Shell Laboratorium, Amsterdam, Netherlands. istudies of these effects are reviewed by: M. M. Davies, Ann. Rep. XLIII, 3 (1946) and L. Kelliner, Rep. Prog. Phys, XV, 1 (1952).

${ }^{2} W$. Gordy, J. Chem. Phys, 7, 93 (1939); R. Mecke, and W. Liittke, $Z$. Elektrochem. 53, 241 (1949).

A. V. Stuart, J. Opt. Soc. Am., 43, 2121953. 